\title{
Age-Related Comparisons of Evolution of the Inflammatory Response After Intracerebral Hemorrhage in Rats
}

\author{
Starlee Lively • Lyanne C. Schlichter
}

Received: 9 February 2012 /Revised: 28 February 2012 / Accepted: 1 March 2012 /Published online: 16 March 2012

(C) The Author(s) 2012. This article is published with open access at Springerlink.com

\begin{abstract}
In the hours to days after intracerebral hemorrhage $(\mathrm{ICH})$, there is an inflammatory response within the brain characterized by the infiltration of peripheral neutrophils and macrophages and the activation of brain-resident microglia and astrocytes. Despite the strong correlation of aging and ICH incidence, and increasing information about cellular responses, little is known about the temporal- and age-related molecular responses of the brain after ICH. Here, we monitored a panel of 27 genes at $6 \mathrm{~h}$ and 1, 3, and 7 days after $\mathrm{ICH}$ was induced by injecting collagenase into the striatum of young adult and aged rats. Several molecules (CR3, TLR2, TLR4, IL-1 $\beta$, TNF $\alpha$, iNOS, IL-6) were selected to reflect the classical activation of innate immune cells (macrophages, microglia) and the potential to exacerbate inflammation and damage brain cells. Most of the others are associated with the resolution of innate inflammation, alternative pathways of macrophage/microglial activation, and the repair phase after acute injury (TGF $\beta$, IL-1 ra, IL-1r2, IL-4, IL-13, IL-4R $\alpha$, IL-13R $\alpha 1$, IL-13R $\alpha 2$, MRC1, ARG1, CD163, CCL22). In young
\end{abstract}

Electronic supplementary material The online version of this article (doi:10.1007/s12975-012-0151-3) contains supplementary material, which is available to authorized users.

S. Lively $\cdot$ L. C. Schlichter

Toronto Western Research Institute, University Health Network,

Toronto, ON, Canada

L. C. Schlichter

Department of Physiology, University of Toronto,

Toronto, ON, Canada

L. C. Schlichter $(\bowtie)$

Toronto Western Hospital, MC9-417,

399 Bathurst Street,

Toronto, ON, Canada M5T 2S8

e-mail: schlicht@uhnres.utoronto.ca animals, the up-regulation of 26 in 27 genes (not IL-4) was detected within the first week. Differences in timing or levels between young and aged animals were detected for 18 of 27 genes examined (TLR2, GFAP, IL- $1 \beta$, IL-1ra, IL1r2, iNOS, IL-6, TGF $\beta$, MMP9, MMP12, IL-13, IL-4R $\alpha$, IL-13R $\alpha 1$, IL-13R $\alpha 2$, MRC1, ARG1, CD163, CCL22), with a generally less pronounced or delayed inflammatory response in the aged animals. Importantly, within this complex response to experimental $\mathrm{ICH}$, the induction of proinflammatory, potentially harmful mediators often coincided with resolving and beneficial molecules.

Keywords Hemorrhagic stroke · Aging brain . Inflammation · Alternative activation · Collagenase . Striatum

\section{Introduction}

Spontaneous intracerebral hemorrhage (ICH) is associated with high mortality and morbidity: $\sim 50 \%$ of patients die within 6 months, and $\sim 80 \%$ of survivors do not regain functional independence $[1,2]$. The greatest risk factor is increasing age, and consequent increases in chronic hypertension, amyloid angiopathy, and the use of anti-thrombotic drugs, followed by hypertension [3-7]. Thus, ICH incidence is expected to rise with the aging population demographic and increasing hypertension rates in younger people [8]. In young adults, hypertensive ICH results in smaller hematoma volumes and better survival rates, but more severe disabilities, suggesting age-related differences in the underlying pathology [9]. Most experimental ICH studies use young healthy animals, but age-related differences are emerging, e.g., evidence that aged animals have altered glial scar formation and microglial recruitment $[10,11]$, reduced 
lesion resolution [11], increased white matter damage [12], more severe edema and autophagy $[10,13]$, and poorer functional recovery $[10,13]$.

ICH is often described as having acute, secondary, and resolution phases. In the acute injury phase (first few hours), blood extravasation forms a hematoma, resulting in the physical destruction of adjacent tissue and mass effects that compress surrounding structures [14]. The secondary phase, which can last for days, includes hematoma expansion and cerebral edema, resulting from blood-brain barrier (BBB) breakdown in the tissue surrounding the clot $[15,16]$ and a prominent inflammatory response with the infiltration of neutrophils and monocytes, activation of resident microglia, and cross talk with other brain cells. These events often occur after hospital admission and are therefore temporally amenable to therapeutic intervention [17-19]. Many studies have focused on the initial capacity of the activated microglia to promote bystander injury; however, the innate immune response in the CNS, as in peripheral tissues, can orchestrate the repair, reconstruction, and resolution of tissue injury. There is a need for studies of the evolution of the inflammatory response over time after ICH and comparisons between young adult and aged animals.

We used real-time RT-PCR to compare the expression of 27 immune-related molecules in young and aged rats at $6 \mathrm{~h}$ and 1,3 , and 7 days after ICH was induced by injecting bacterial collagenase into the striatum, a model we have previously used to study inflammation and damage to gray and white matter [11, 12, 20-23]. Our salient earlier findings (illustrated in the summary image in Electronic Supplementary Material (ESM) Fig. S1) are as follows. Neutrophils infiltrate the hematoma only and at early times ( 1 and 3 days) and then die off. By day 3, there is extensive neuron death, damage to myelin and axons, and infiltration of the damaged axon bundles by activated microglia and macrophages within and at the edge of the hematoma. Over the first several days, the hematoma becomes filled with activated microglia and macrophages, and a glial scar forms at the lesion edge, with a band of activated microglia and macrophages surrounded by reactive astrocytes. Therefore, we selected this time course to analyze the expression of inflammationrelated genes, including pro- and anti-inflammatory mediators, tissue remodeling enzymes, and markers of different states of macrophage/microglia activation.

\section{Materials and Methods}

\section{Induction of Intracerebral Hemorrhage}

All procedures were performed on male Sprague-Dawley rats in accordance with the guidelines established by the Canadian Council on Animal Care and approved by the
Animal Care Committee at the University Health Network. Young adult rats $(n=36)$ were 3-4 months old and 350 $500 \mathrm{~g}$ at the time of surgery (Charles River, St-Constant, Canada). Aged rats $(n=35)$ were purchased at $10-11$ months old from Harlan Laboratories (Mississauga, Canada) and maintained in our animal facility until $20-21$ months old and $450-600 \mathrm{~g}$. With a mean life span of $\sim 25$ months for this rat strain [24], this corresponds to early old age in humans. ICH was induced in the anterior striatum (caudate + putamen), as we recently described $[12,20]$. In brief, rats were anesthetized with isoflurane (3.5\% induction, $1.5 \%$ maintenance), placed in a small-animal stereotaxic instrument (David Kopf Instruments, Tujunga, CA), and a 1-mm diameter burr hole was drilled $0.2 \mathrm{~mm}$ anterior and $3.5 \mathrm{~mm}$ lateral to bregma. A 30-gauge needle attached to a micropump (UltraMicroPump II, World Precision Instruments, Sarasota, FL) was lowered $6 \mathrm{~mm}$ ventral to the skull surface into the right caudate putamen.

ICH was evoked by injecting bacterial type IV collagenase (Sigma-Aldrich, Oakville, Canada) to rupture blood vessels. This is a well-characterized model [25-28] that we have used extensively [11, 12, 20-23] (and see ESM Fig. S1). Collagenase was diluted in sterile physiological saline, and the injected amounts $(0.2 \mathrm{U}$ for young adult rats, $0.15 \mathrm{U}$ for aged rats; both in $0.5 \mu \mathrm{L}$ saline) were chosen to produce lesions that were limited to the striatum (examples shown in Fig. 1a). Using the lower dose in aged rats minimized mortality and created lesion sizes that were comparable to those in young adult rats [11]. Note that lesion size cannot be measured in the same animals used for real-time RT-PCR because the whole striatum is rapidly harvested to preserve the mRNA. However, visual inspection of the hematoma before harvest did not identify apparent differences in size between young and aged animals. Control animals were time- and age-matched sham-operated rats that received intrastriatal injections of $0.5 \mu \mathrm{L}$ saline. In all cases, the injection rate was $0.25 \mu \mathrm{L} / \mathrm{min}$, after which the needle was left in place for $5 \mathrm{~min}$ to prevent solution reflux. Core body temperature was maintained at $36.5^{\circ} \mathrm{C}$ throughout the surgery and recovery period using a thermostat-regulated heating pad. All rats survived and regained consciousness within $10 \mathrm{~min}$. As expected, all rats with an ICH (but not salineinjected control rats) demonstrated an ipsilateral turning bias, while their grooming and feeding behavior appeared normal.

Tissue Preparation

Cohorts of animals were killed by an overdose of isoflurane at $6 \mathrm{~h}$ and 1, 3, or 7 days after surgery. For real-time RTPCR, animals were perfused transcardially with $120 \mathrm{~mL}$ of cold PBS (0.1 mol/L phosphate-buffered saline, $\mathrm{pH} 7.5)$. Brains were removed, placed in a rat brain matrix (Ted Pella 
A. ICH; young adult
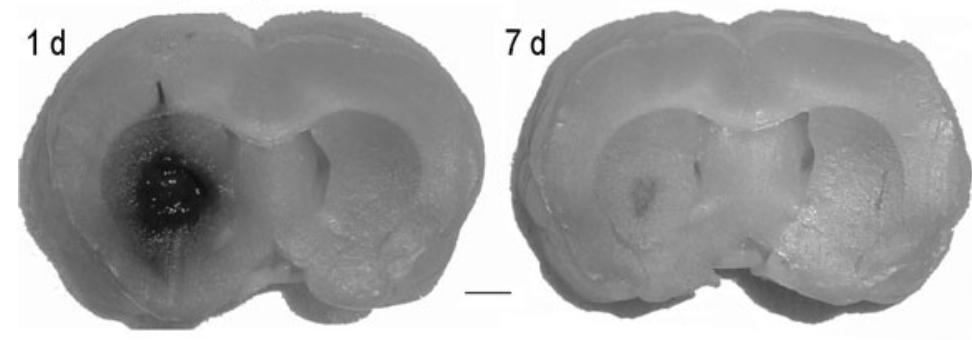

B. Saline control (young)

C.

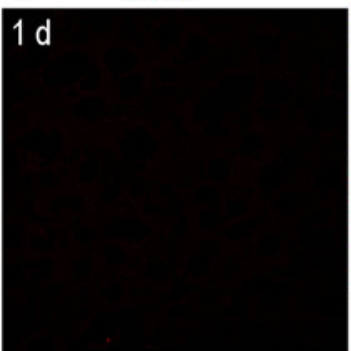

MBP dMBP

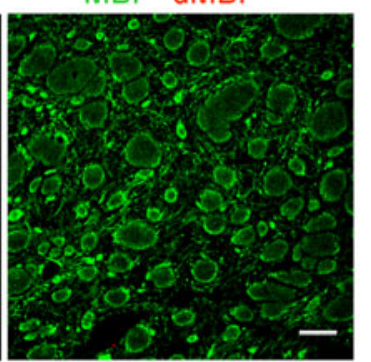

$3 d$

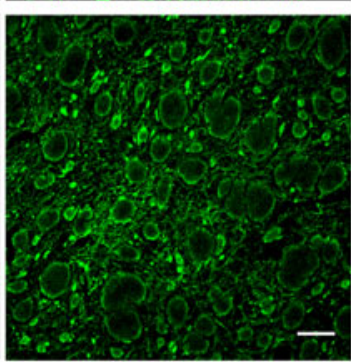

$7 d$

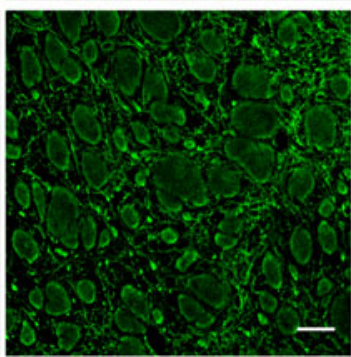

D.
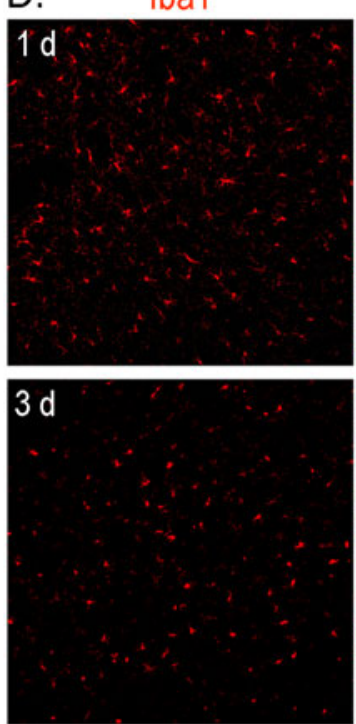

$7 d$

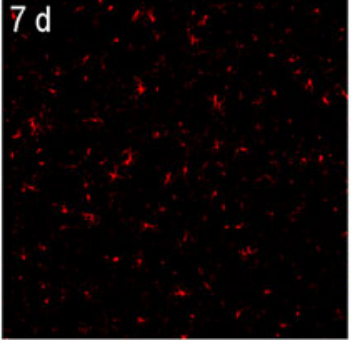

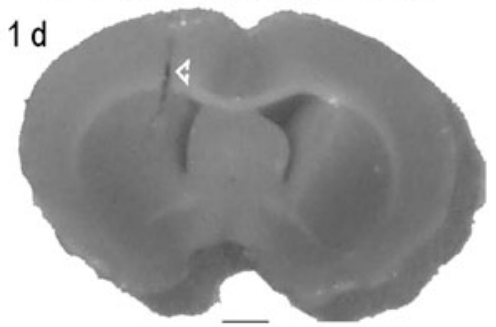

MBP Iba1
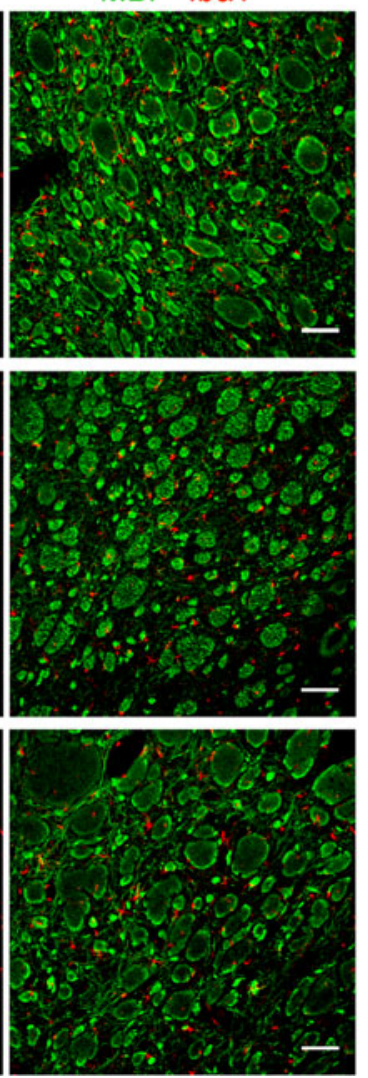

Fig. 1 The collagenase model of ICH and the use of the contralateral striatum for animal- and age-matched comparisons. a A representative young adult rat showing that stereotaxic injection of type IV collagenase produced a hematoma that was restricted to the ipsilateral striatum. Much of the blood clot has been resorbed by day 7. b In a salineinjected control rat, the needle penetration track is seen (arrowhead) without bleeding in the striatum. $\mathbf{c}$ Representative confocal images of

Inc., Redding, CA), submerged in ice-cold PBS, and cut $2 \mathrm{~mm}$ anterior and $2 \mathrm{~mm}$ posterior to the needle entry site, which was easily identified on the brain surface. Each 4mm-thick coronal section was divided along the midline into an ipsilateral (hematoma-bearing) and contralateral hemisphere, and the striatum was isolated from each slice and snap-frozen on dry ice. Tissue was stored at $-80^{\circ} \mathrm{C}$ until used for RNA extraction. For immunohistochemistry, animals were perfused transcardially with PBS (as above), followed by fixative $(120 \mathrm{~mL}$ cold PBS-buffered $4 \%$ the contralateral striatum at 1,3 , and 7 days after ICH show normal white matter bundles labeled with myelin basic protein $(M B P$, green $)$ and lack of degraded MBP (red). d In the contralateral striatum at 1, 3, and 7 days after ICH, microglia, identified with Ibal (red) are of ramified morphology and broadly distributed between the white matter tracts. Scale bars, $500 \mu \mathrm{m}$

paraformaldehyde; EMD Biosciences, Gibbstown, NJ). Brains were removed and processed at $4{ }^{\circ} \mathrm{C}$ : first in fixative $(24 \mathrm{~h})$, then in $10 \%$ sucrose in PBS $(24 \mathrm{~h})$, and finally in $30 \%$ sucrose in PBS until the brains sank. The cryoprotected brains were placed in a brain matrix; coronal slices were made at 3,6 , and $9 \mathrm{~mm}$ from the anterior and then mounted in Tissue Freezing Medium (Somagen Diagnostics, Edmonton, Canada) and stored at $-40^{\circ} \mathrm{C}$. Frozen brain sections (16 $\mu \mathrm{m}$ thick) were made on a cryostat (model CM350S, Leica, Richmond Hill, Canada), collected on gelatin-coated 
slides ( $1 \%$ gelatin, $0.5 \%$ chromium potassium sulfate), and stored at $-40^{\circ} \mathrm{C}$ until used.

Quantitative Real-Time Reverse Transcriptase Polymerase Chain Reaction

Gene-specific primers (Table 1) were designed using "Primer3Output" (http://frodo.wi.mit.edu/cgi-bin/primer3/ primer3_www.cgi). Total RNA was extracted using the TRIzol method (Invitrogen), followed by further purification using the RNeasy Mini Kit (Qiagen, Mississauga, ON), and a two-step reaction was performed according to the manufacturer's instructions (Invitrogen). In brief, total RNA $(0.8 \mu \mathrm{g})$ was reverse-transcribed in $20 \mu \mathrm{L}$ volume using $200 \mathrm{U}$ of SuperScriptII RNase reverse transcriptase, with $0.5 \mathrm{mM}$ dNTPs and $0.5 \mu \mathrm{M}$ oligo dT (Invitrogen). Amplification was performed on an ABI PRISM 7900 Sequence Detection System (PE Biosystems, Foster City, CA) at $95^{\circ} \mathrm{C}$ for $10 \mathrm{~min}, 40$ cycles at $95^{\circ} \mathrm{C}$ for $15 \mathrm{~s}$, and $56^{\circ} \mathrm{C}$ for 20 s. "No-template" and "no-amplification" controls were included for each gene, and melt curves showed a single peak, confirming specific amplification. The threshold cycle $\left(C_{\mathrm{T}}\right)$ for each gene was normalized to that of the housekeeping gene, hypoxanthine guanine phosphoribosyl transferase (HPRT1), which we have found to be especially stable in the brain. Results in Figs. 2, 3, 4, 5, 6, and 7 are mRNA expression relative to the level in control rats injected with saline (mean \pm SEM, $n=4-6$ rats per age group per time point). For statistical analysis, two-way ANOVA and Bonferroni post hoc tests were conducted using GraphPad Prism ver 5.01 (GraphPad Software, San Diego, CA).

Immunohistochemistry

Frozen brain sections mounted on slides were thawed at room temperature and rehydrated for $20 \mathrm{~min}$ in PBT buffer ( $0.1 \mathrm{~mol} / \mathrm{L}$ PBS, $\mathrm{pH} 7.5,0.1 \%$ bovine serum albumin, $0.2 \%$ Triton X-100). To reduce nonspecific antibody binding, slides were blocked for $2 \mathrm{~h}$ in $10 \%$ donkey serum in PBT. Brain sections were then incubated overnight at room temperature in PBT buffer that contained one or two of the following primary antibodies. Axon bundles were labeled with a mouse monoclonal antibody against myelin basic protein (MBP; 1:100; Sigma-Aldrich), and regions of myelin damage or demyelination were identified with a rabbit polyclonal antibody that recognizes only degraded MBP (dMBP, 1:250; Chemicon, Temecula, CA). The microglia were labeled with rabbit polyclonal anti-ionized calciumbinding adapter-1 (Iba1; 1:1,000; Wako, Japan) or a mouse monoclonal anti-ED1 antibody (1:100; Serotec, Raleigh, NC) which labels CD68 in the lysosomes of activated phagocytic microglia/macrophages. Microvessels were labeled with a rabbit polyclonal antibody against collagen
Table 1 Primers used for real-time RT-PCR

\begin{tabular}{|c|c|c|}
\hline Gene & $\begin{array}{l}\text { GenBank } \\
\text { accession no. }\end{array}$ & Primer sequences \\
\hline \multirow[t]{2}{*}{ ARG1 } & \multirow[t]{2}{*}{ NM_017134.1 } & FP: GTCTGTGGGAAAAGCCAATG \\
\hline & & RP: TTGCCATACTGTGGTCTCCA \\
\hline \multirow[t]{2}{*}{ CR3 } & \multirow[t]{2}{*}{ NM_012711 } & FP: TGCTGAGACTGGAGGCAAC \\
\hline & & RP: CTCCCCAGCATCCTTGTTT \\
\hline \multirow[t]{2}{*}{ CCL22 } & \multirow[t]{2}{*}{ NM_057203.1 } & FP: AGGATGCTCTGGGTGAAGAA \\
\hline & & RP: TAGGGTTTGCTGAGCCTTGT \\
\hline \multirow[t]{2}{*}{ CD163 } & \multirow[t]{2}{*}{ NM_001107887.1 } & FP: ATCACAGCATGGCACAGGT \\
\hline & & RP: TCCAGATCATCCGTCTTCG \\
\hline \multirow[t]{2}{*}{ CHI3L1 } & \multirow[t]{2}{*}{ NM_053560 } & FP: GGGCAGTGGATTTGGATG \\
\hline & & RP: TGCAAGTGACCAGACTCCTG \\
\hline \multirow[t]{2}{*}{ GFAP } & \multirow[t]{2}{*}{ NM_017009.1 } & FP: CAGCTTCGAGCCAAGGAG \\
\hline & & RP: TGTCCCTCTCCACCTCCA \\
\hline \multirow[t]{2}{*}{ ICE } & \multirow[t]{2}{*}{ NM_012762 } & FP: CCAACCACTGAAAGGGTGA \\
\hline & & RP: GCATGATTCCCAACACAGG \\
\hline \multirow[t]{2}{*}{ IL-1 $\beta$} & \multirow[t]{2}{*}{ NM_031512 } & FP: TGACCCATGTGAGCTGAAAG \\
\hline & & RP: AGGGATTTTGTCGTTGCTTG \\
\hline \multirow[t]{2}{*}{ IL-1ra/IL-1rn } & \multirow[t]{2}{*}{ NM_022194 } & FP: GGGAAAAGACCCTGCAAGA \\
\hline & & RP: GTGGATGCCCAAGAACACA \\
\hline \multirow[t]{2}{*}{ IL-1r2 } & \multirow[t]{2}{*}{ NM_053953.1 } & FP: GTGATCATTTCTCCCCTGGA \\
\hline & & RP: CACGATGGTGTTGGAAGATG \\
\hline \multirow[t]{2}{*}{ IL-6 } & NM_012589 & FP: CAGGAACGAAAGTCAACTCCA \\
\hline & & RP: ATCAGTCCCAAGAAGGCAACT \\
\hline IL-4 & NM_201270.1 & FP: CAAGGAACACCACGGAGAA \\
\hline & & RP: TTCAGACCGCTGACACCTC \\
\hline IL-4r $\alpha$ & NM_133380.2 & FP: TCCGCACTTCTACGTGTGAG \\
\hline & & RP: AGACCACAGTTCCAGCCAGT \\
\hline IL-13 & NM_053828.1 & FP: TCTGTGCAGCCCTGGAAT \\
\hline & & RP: GCGGAAAAGTTGCTTGGA \\
\hline IL-13r $\alpha 1$ & NM_145789.2 & FP: AGAAACATGGAGGGTGCAAG \\
\hline & & RP: CACTGCGACAAAGACTGGAA \\
\hline IL-13r $\alpha 2$ & NM_145789.2 & FP: AGAAACATGGAGGGTGCAAG \\
\hline & & RP: CACTGCGACAAAGACTGGAA \\
\hline iNOS & NM_012611 & FP: GCTACGCCTTCAACACCAA \\
\hline & & RP: GCTTGTAACCACCAGCAGT \\
\hline MRC1 & NM_001106123 & FP: AAGGTTCCGGTTTGTGGAG \\
\hline & & RP: TGCATTGCCCAGTAAGGAG \\
\hline MMP-3 & NM_133523 & FP: TCCCACAGAATCCCCTGA \\
\hline & & RP: CGCCAAAAGTGCCTGTCT \\
\hline MMP-9 & NM_031055 & FP: CTGCCTGCACCACTAAAGG \\
\hline & & RP: GAAGACGAAGGGGAAGACG \\
\hline MMP-12 & NM_053963 & FP: CTGGGCAACTGGACACCT \\
\hline & & RP: CTACATCCGCACGCTTCA \\
\hline TIMP1 & NM_053819 & FP: GGTTCCCCAGAAATCATCG \\
\hline & & RP: GGAAACCTGTGGCATTTCC \\
\hline TACE & NM_020306 & FP: TGTGAGCAGTTTCTCGAACG \\
\hline & & RP: AAAGGCACCAAAGTGGTCAG \\
\hline TGF $\beta 1$ & NM_021578.1 & FP: ATACGCCTGAGTGGCTGTC \\
\hline & & RP: GCCCTGTATTCCGTCTCCT \\
\hline TLR2 & NM_198769.2 & FP: CTGCAAGCTCTTTGGCTCTT \\
\hline & & RP: ACACACCAGCAGCATCACAT \\
\hline TLR4 & NM_019178.1 & FP: TGCTCAGACATGGCAGTTTC \\
\hline & & RP: GCGATACAATTCGACCTGCT \\
\hline
\end{tabular}


Table 1 (continued)

\begin{tabular}{lll}
\hline Gene & $\begin{array}{l}\text { GenBank } \\
\text { accession no. }\end{array}$ & Primer sequences \\
\hline TNF- $\alpha$ & NM_012675 & FP: GCCCACGTCGTAGCAAAC \\
& & RP: GCAGCCTTGTCCCTTGAA \\
HPRT-1 & NM_012583.2 & FP: CAGTACAGCCCCAAAATGGT \\
& & RP: CAAGGGCATATCCAACAACA \\
\hline
\end{tabular}

$F P$ forward primer, $R P$ reverse primer

type IV (CgIV; 1:250; Abcam, Cambridge, MA), a major constituent of the basal lamina in cerebral blood vessels [29]. After labeling with primary antibodies, brain sections were washed in PBS $(3 \times 10 \mathrm{~min})$ and incubated for $2 \mathrm{~h}$ at room temperature in the dark with appropriate secondary antibodies diluted to 1:400 in PBT, i.e., DyLightTM488conjugated AffiniPure donkey anti-mouse IgG, DyLightTM594-conjugated AffiniPure donkey anti-rabbit or anti-mouse (Jackson Immunoresearch, Mississauga, Canada). To stain cell nuclei, 4'-6-diamidino-2-phenylindole (DAPI; 1:5,000; Sigma-Aldrich) was applied for $5 \mathrm{~min}$. After washing in PBT $(3 \times 20 \mathrm{~min})$, slides were coverslipped using Vectashield mounting medium (Cedarlane, Burlington, Canada) and stored in the dark at $4^{\circ} \mathrm{C}$. All images shown are representative examples of at least three animals at each indicated time point.

\section{Results}

Because ICH commonly occurs in deep nuclei of the cerebrum, pons, cerebellum, and in deep white matter [2], we have been studying the anterior striatum of the rat (caudate and putamen) [11, 12, 20-23]. After collagenase is injected into the striatum, a hematoma rapidly develops and then the blood clot is gradually resorbed over several days (Fig. 1a), leaving a lesion with neuron death, white matter damage, BBB disruption, and extensive accumulation of the activated microglia/macrophages (the collective term reflects that the cells become morphologically indistinguishable after microglia processes retract). ESM Fig. S1 shows examples of immunostaining to illustrate the temporal-spatial evolution of the ICH lesion. In saline-injected control rats (Fig. 1b), the needle track can be seen, but there is no bleeding in the striatum. The contralateral striatum was uninjured (Fig. 1c, d); it showed normal MBP staining of white matter tracts (bundles of penetrating axons in crosssection), no dMBP, and normal microglia with a "resting" ramified morphology. Therefore, over the 7-day time course of the present study, we routinely compared the damaged ipsilateral striatum with saline-injected control animals and used the contralateral striatum as an animal- and time- matched internal reference [20, 23]. Importantly, the collagenase dose was titrated to obtain comparable sized lesions in young and aged rats (examples in Fig. 2a) [11].

\section{Time-Dependent Glial Cell Activation in Young and Aged Rats}

The inflammatory response after ICH is characterized by neutrophil and monocyte infiltration, activation of endogenous microglia and astrocytes, and production of numerous inflammatory mediators, including cytokines and matrix metalloproteases (MMPs). We previously quantified the time-dependent accumulation of activated microglia/macrophages over the first week in this ICH model $[12,20,22]$ (and see ESM Fig. S1). In young rats, most of the blood clot was resorbed by 7 days (Fig. 1a), presumably due to phagocytosis. Interestingly, activated microglia/macrophages in the lesion were not homogeneous (Fig. 2a); Iba1-labeled cells filled the lesion, while those labeled with the lysosomal marker, ED1 (an indicator of phagocytic capacity) were more concentrated at the periphery, where we previously showed a zone of dramatic neuron loss [11, 22] (and see ESM Fig. S1). Despite ensuring initially similar-sized hematomas in young adult and aged rats, by 7 days the lesion of aged rats showed less Iba1 labeling and fewer total cell numbers (nuclei stained with DAPI). ED1 staining was more diffuse and extended further into the surrounding striatum. Based on these results and previously reported differences between young and aged rats (see "Discussion"), we examined the time course ( $6 \mathrm{~h}, 1,3$, and 7 days) of induction of 27 genes associated with inflammation.

We assessed gene transcript expression in each ipsilateral and contralateral striatum (four to six rats per group). In order to identify ICH-induced changes, values on the $Y$-axes (Figs. 2, 3, 4, 5, 6, and 7) indicate fold changes normalized to age- and time-matched, saline-injected control animals (set to 1.0, dashed line in each panel). Because increased basal levels of cytokines (TNF $\alpha$, IL-1 $\alpha$, IL-1 $\beta$, IL-6, TGF $\beta$ ) have been reported in the aging naive rodent brain [30-32], we have not compared basal levels in young and aged control animals.

First, we monitored several molecules that are commonly used to assess gliosis and inflammation after acute brain injury [33-35], i.e., the astrocyte marker, glial fibrillary acidic protein (GFAP), and the microglia/macrophage markers, complement receptor $3(\mathrm{CR} 3 / \mathrm{CD} 11 \mathrm{~b})$ and Toll-like receptors, TLR2 and TLR4. Over the first week after ICH, GFAP and CR3 increased in the damaged ipsilateral striatum of young rats (Fig. 2b) and reached levels several-fold higher than saline-injected controls. The main difference in aged rats was the lack of up-regulation of GFAP at 1 day, which might reflect slower development of 

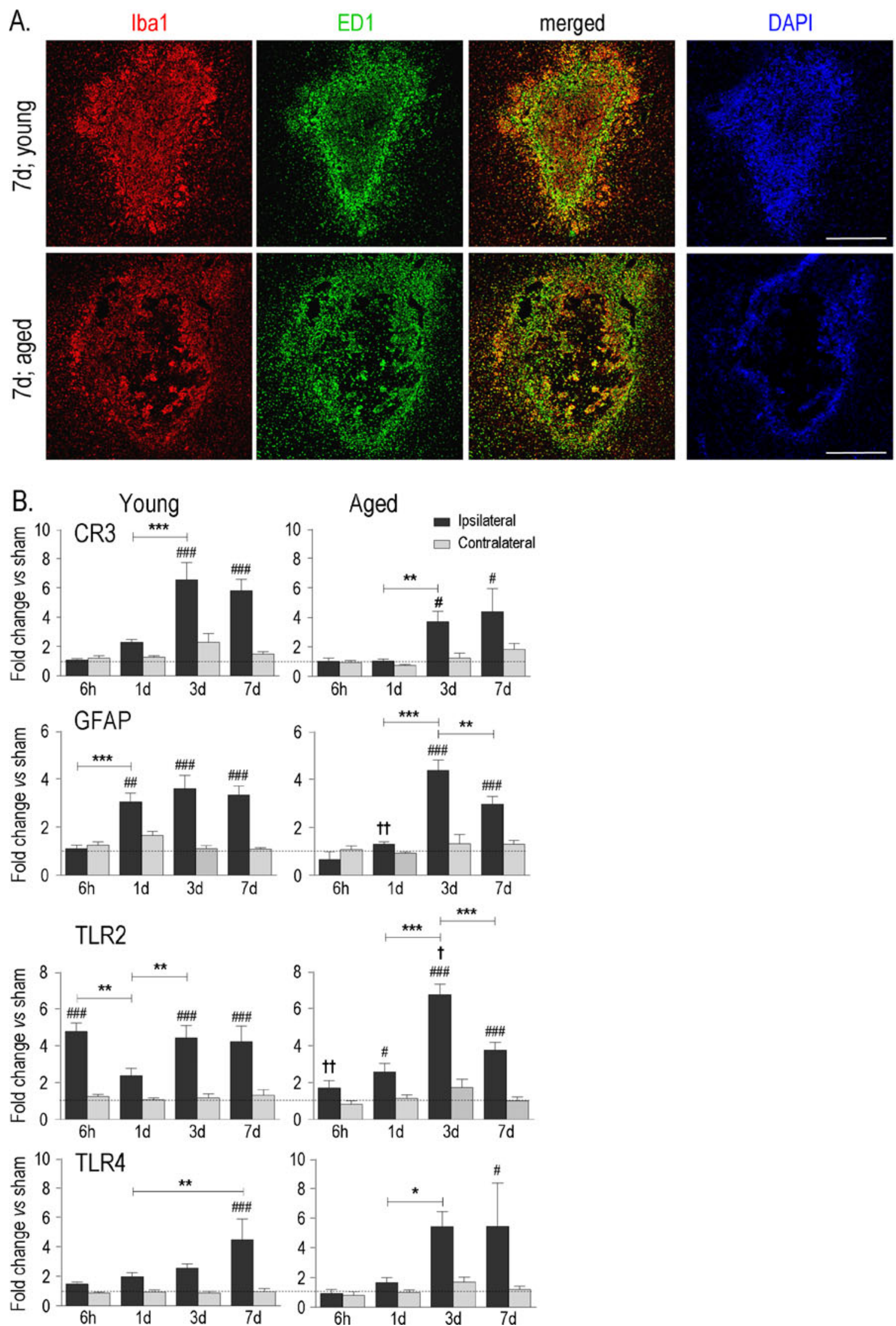

(Caption on next page) 
Fig. 2 Time-dependent glial cell accumulation and activation. a Low magnification coronal images of the hematoma at 7 days post-ICH in representative young adult and aged rats. Microglia and macrophages were labeled with Iba1 (red) and the lysosomal marker, ED1 (green). Adjacent serial sections were stained with the nuclear dye, DAPI (blue). Scale bars, $500 \mu \mathrm{m}$. b Expression of several markers of glial responses after ICH: astrocyte marker, glial fibrillary acidic protein (GFAP); microglia/macrophage markers, complement receptor 3 (CR3), Toll-like receptors, TLR2 and TLR4. After two-way ANOVA with Bonferroni correction, the following significant intergroup differences are indicated: ${ }^{\#}$ In ipsilateral vs. contralateral striatum; ${ }^{*}$ With time; ${ }^{\dagger}$ Between young adult and aged rats. One symbol of any type signifies $p<0.05$; two symbols, $p<0.01$; three symbols, $p<0.001$

a glial scar, and correlates with our earlier finding that white matter injury extends further in aged rats [12]. While CR3 was suggestive of a lower expression in aged animals, more data would be needed. The up-regulation of TLR2 and
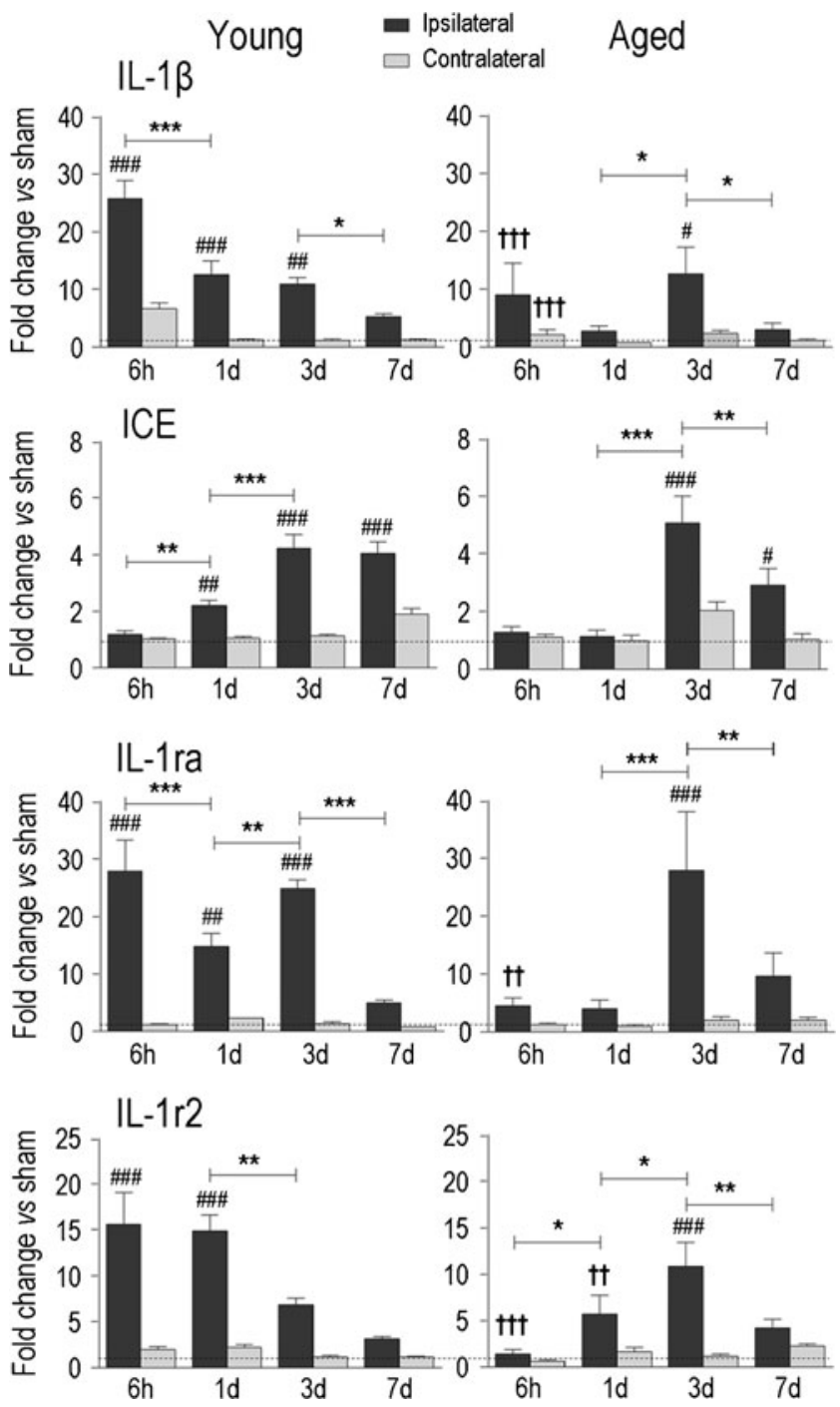

Fig. 3 Temporal expression of IL-1 $\beta$ and its regulatory molecules in young adult and aged rats after ICH. Transcript expression was measured, analyzed, and expressed as in Fig. $2 \mathrm{~b}$ for interleukin- $1 \beta(I L-1 \beta)$, interleukin-1-converting enzyme (ICE), the endogenous IL-1 receptor antagonist $(I L-1 r a)$, and type 2 IL-1 receptor $(I L-1 r 2)$
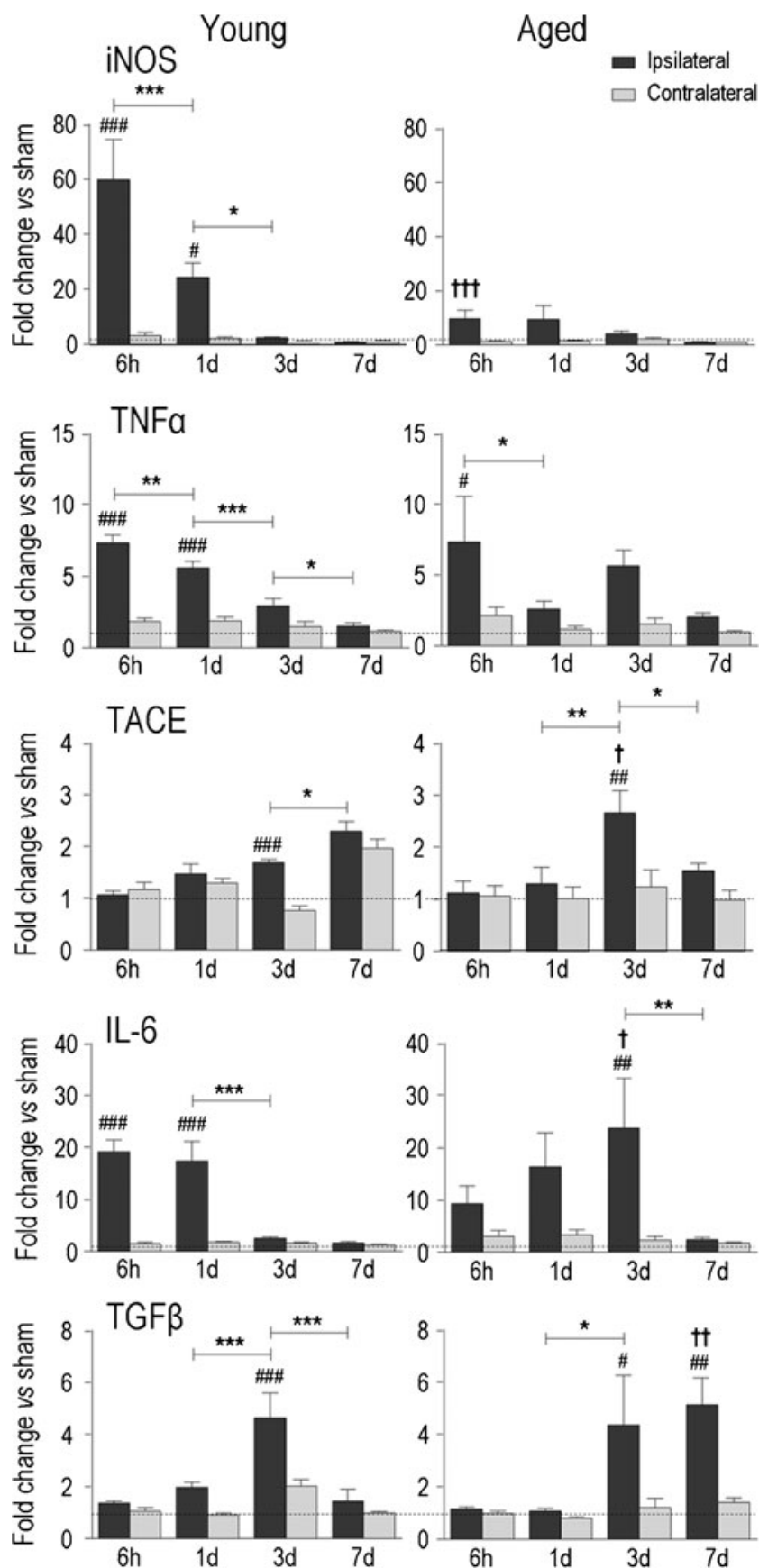

Fig. 4 Temporal expression of hallmark inflammatory molecules after ICH in young adult and aged rats. Transcript expression was measured, analyzed, and expressed as in Fig. $2 \mathrm{~b}$ for inducible nitric oxide synthase $\left(i N O S / N O S_{2}\right)$, tumor necrosis factor- $\alpha(T N F \alpha)$, TNF $\alpha-$ converting enzyme (TACE), interleukin-6 (IL- 6$)$, and transforming growth factor- $\beta(T G F \beta)$

TLR4 expression further indicates an innate immune response, but interestingly, in young animals, TLR2 clearly preceded TLR4 induction ( $6 \mathrm{~h}$ vs. 7 days). Activation of microglia is thought to depend on the TLR2/TLR4 activation sequence, with TLR2 activation decreasing TLR4 transcription and downstream expression of several 

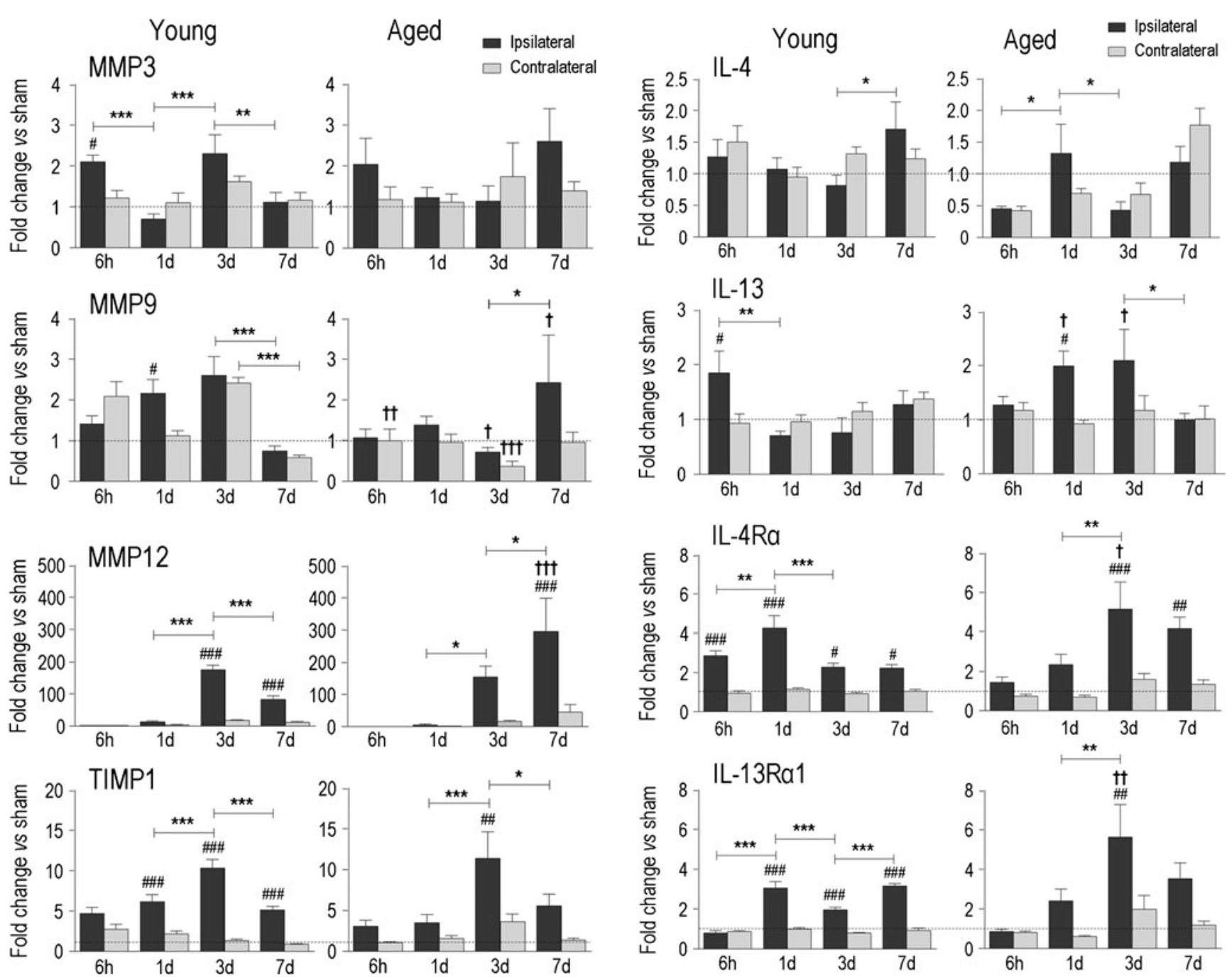

Fig. 5 Temporal expression of matrix metalloprotease-related genes after IHC in young adult and aged rats. Transcript expression was measured, analyzed, and expressed as in Fig. $2 \mathrm{~b}$ for the matrix metalloproteases, MMP3, MMP9, MMP12, and the endogenous tissue inhibitor of metalloproteinases (TIMP1)

phagocytosis-related receptors (CR3, MHCII, FcyR) [36]. In aged animals, TLR2 and TLR4 showed a delay and a similar time course, with the highest expression on days 3 and 7 (none of the four genes was up-regulated in the contralateral striatum).

Time- and Age-Dependent Induction of Pro-inflammatory Genes and MMPs

The pro-inflammatory cytokine, IL-1 $\beta$, is one of the earliest mediators induced and is considered a principal orchestrator of inflammation after acute CNS injury [37]. IL-1 $\beta$ function requires interleukin-1 converting enzyme (ICE/caspase 1) which cleaves pro-IL-1 $\beta$ to its mature, active form $[38,39]$. The bioavailability of IL-1 is reduced by specific decoy receptors expressed on the macrophage/microglia surface

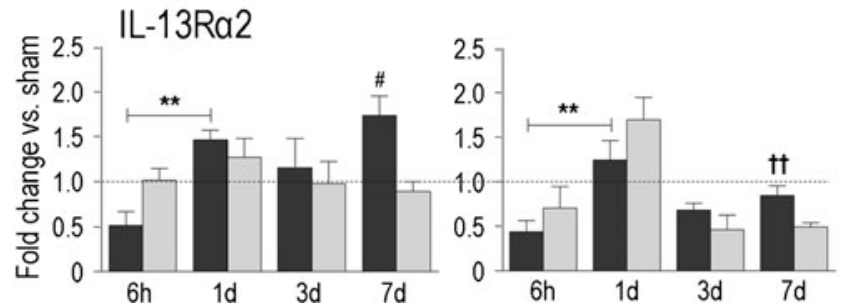

Fig. 6 Temporal expression in young adult and aged rats of genes involved in alternative macrophage/microglia activation. Transcript expression was measured, analyzed, and expressed as in Fig. $2 b$ for interleukin-4 (IL-4), interleukin-13 (IL-13), and their receptors, IL$4 \mathrm{R} \alpha, \mathrm{IL}-13 \mathrm{R} \alpha 1, \mathrm{IL}-13 \mathrm{R} \alpha 2$

or secreted into the local environment, i.e., the IL-1 receptor antagonist (IL-1ra), which binds to the receptors without inducing a cellular response [40], and the type 2 IL-1 receptor (IL-1r2), which acts as a decoy receptor [41]. In young animals, there was a marked and rapid IL-1 $\beta$ induction after ICH ( $\sim 25$-fold increase over controls by $6 \mathrm{~h})$, after which the expression progressively declined (Fig. 3). ICE upregulation was lower (at most $\sim 4$-fold) and lagged behind, 

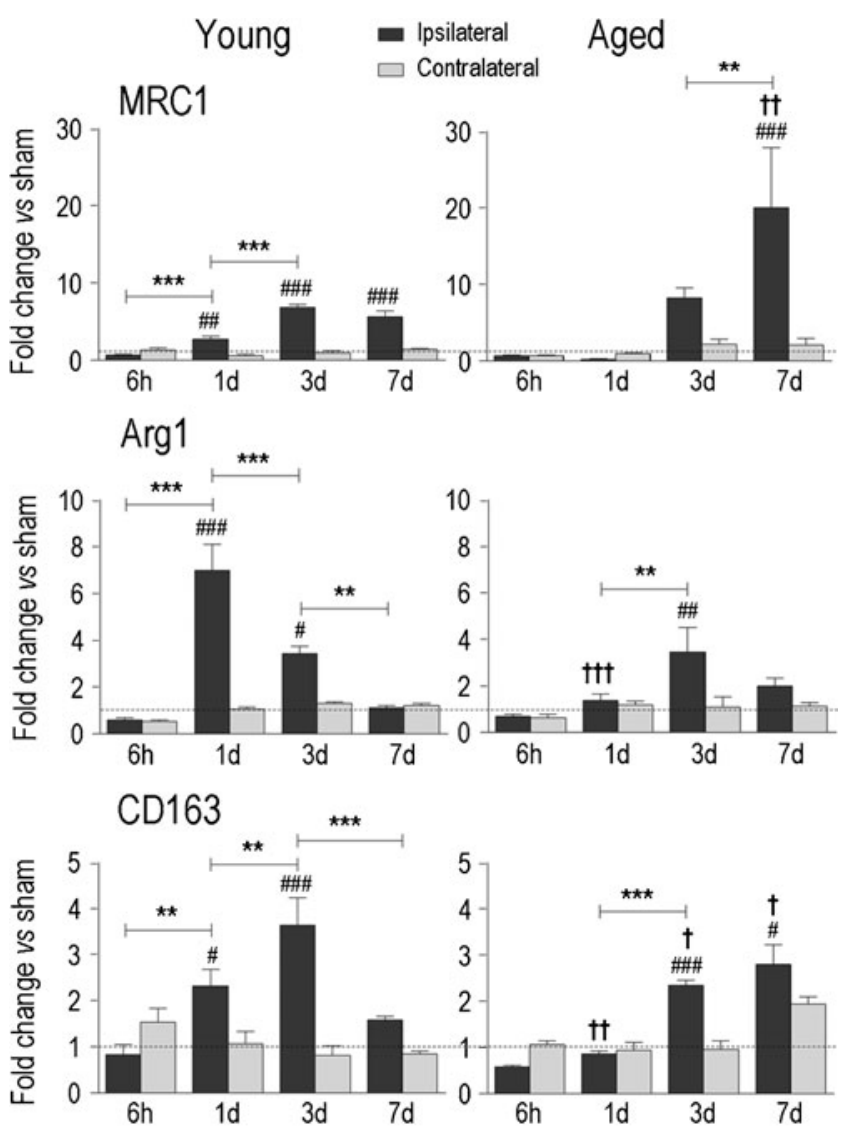

CCL22
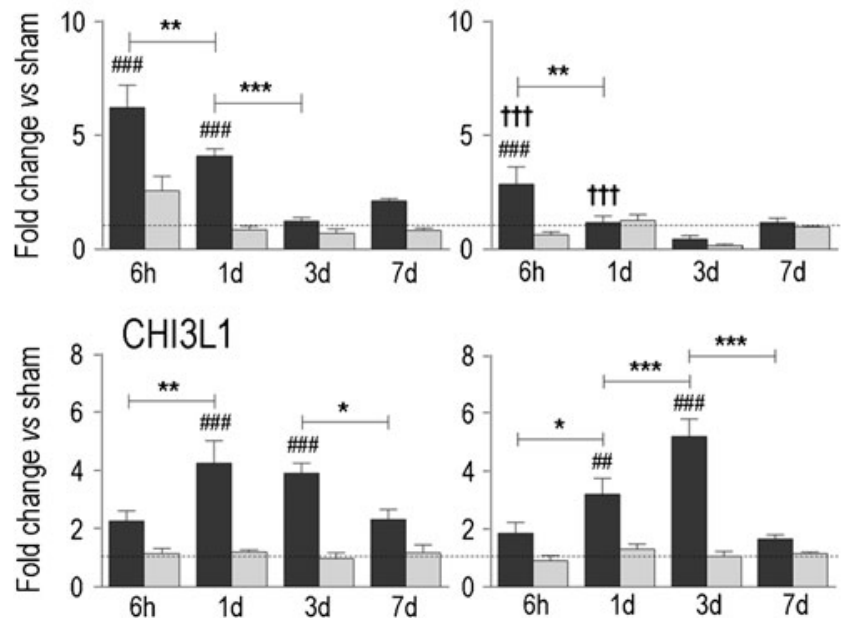

Fig. 7 Temporal expression of markers of alternative activation in young adult and aged rats. Transcript expression was measured, analyzed, and expressed as in Fig. 2b for mannose receptor-1 (MRC1), arginase 1 ( $A R G 1)$, the haptoglobin-hemoglobin scavenger receptor (CD163), chemokine ( $\mathrm{C}-\mathrm{C}$ motif) ligand 22 (CCL22), and chitinase 3like 1 (CHI3L1)

increasing from 1 to 3 days. In aged animals, IL-1 $\beta$ was lower $(\sim 10$-fold increase at $6 \mathrm{~h})$, and ICE induction was delayed until day 3. Striking age-related differences were seen for the endogenous antagonists, IL-1 ra and IL-1r2. Both showed a dramatic and early induction in young rats; for instance, at $6 \mathrm{~h}$, the increases were $\sim 27$-fold for IL-1 ra and $\sim 15$-fold for IL-1r2. In aged rats, neither antagonist was significantly elevated until 3 days, which suggests that functionally active IL-1 $\beta$ might be elevated in the aged (NB: In the contralateral striatum, there was no induction of ICE, IL1ra or IL-1r2, while IL-1 $\beta$ was increased slightly at $6 \mathrm{~h}$ in young animals).

Inducible nitric oxide synthase (iNOS/NOS 2 ) produces nitric oxide which can contribute to the neurotoxic capacity of activated microglia and macrophages [42-45]. A striking age-related difference in iNOS induction was seen (Fig. 4). In young adult rats, iNOS expression increased rapidly and dramatically after ICH ( $\sim 60$-fold at $6 \mathrm{~h})$ and then declined over the next 3 days. In contrast, induction in the aged (ipsilateral vs. contralateral) was not statistically significant at any time examined. Tumor necrosis factor- $\alpha(\mathrm{TNF} \alpha)$ is an early orchestrator of the inflammatory response after acute brain injury [46] and is activated by the TNF $\alpha$ converting enzyme, TACE/ADAM17 [47]. In young rats, TNF $\alpha$ induction followed a similar trend to IL-1 $\beta$ : rapid upregulation ( $6 \mathrm{~h}$ and 1 day) and a time-dependent decline. In aged animals, TNF $\alpha$ was increased only at $6 \mathrm{~h}$. Interestingly, TACE was only increased at 3 days and reached a higher level in aged animals. Interleukin-6 (IL-6) is a pleiotropic cytokine, and its expression is regulated by the classical IL1 pathway [48]. In young rats, IL-6 was markedly elevated early after ICH (15- to 20-fold higher than controls at $6 \mathrm{~h}$ and 1 days) and then declined to baseline by 3 days. In aged rats, IL-6 induction showed a gradual increase and peaked at 3 days. Transforming growth factor- $\beta$ (TGF $\beta$ ) is thought to promote the damage resolution phase after acute CNS injuries [49], including glial scar formation [50]. In young rats, TGF $\beta$ increased transiently at 3 days, but elevation was more prolonged in aged rats ( 3 and 7 days).

MMPs contribute to extracellular matrix remodeling and cleavage of precursor molecules, but their elevation after ICH also correlates with blood BBB disruption, hematoma expansion, and edema (reviewed in [51]). There were marked increases in MMP12 in both age groups (150- to 200 -fold over control rats), which peaked at 3 days in the young but continued to increase at 7 days in the aged animals (Fig. 5). In contrast, there was little change in MMP3 and MMP9 in the young rats (at most a 2- to 2.5-fold increase over control rats), and they were not up-regulated in aged rats. After a slight increase in MMP3 at $6 \mathrm{~h}$ in the young animals, an apparent oscillation with time (lower at 1 and 7 days) did not significantly differ from controls. The small changes in MMP9 were difficult to interpret because the levels apparently increased and oscillated in the contralateral striatum. The endogenous tissue inhibitor of matrix metalloproteases (TIMP1), which regulates the activity of all three MMPs, was elevated on days 1,3 , and 7 in the young, but only on day 3 in aged rats. 
Time-and Age-Dependent Induction of Resolving and Alternative Activation Genes

The initial pro-inflammatory phase after acute injury is characterized by classical (also called M1) activation of macrophages and microglia. This is followed by resolution of the defense response and a repair phase, with changes in the state of macrophages/microglia to what is variously called M2, alternative activation, or acquired deactivation, states that are most readily defined by stimuli and outcomes in vitro (reviewed in $[52,53]$ ). While recognizing that multiple stimuli are present after acute damage in vivo, for simplicity, we will use the term alternative activation when describing resolving and repair genes. The observed spatial differences in Ibal and ED1 expression in activated microglia/macrophages (Fig. 2a), and differing temporal expression of TLR2 and TLR4 between young and aged rats (Fig. 2b), point to a complexity in their activation states after ICH. We first analyzed changes in the expression of two known inducers of alternative macrophage/microglia activation (IL-4 and IL-13) and the three receptors through which they act: IL-4R $\alpha$, IL$13 \mathrm{R} \alpha$, and IL-13R $\alpha 2$ (Fig. 6). IL-13, IL-4R $\alpha$, and IL-13R $\alpha 1$ increased above control levels, and this occurred later in aged rats, i.e., IL-4R $\alpha$ at 1 and 3 days in young vs. 3 and 7 days in aged; IL-13R $\alpha 1$ at 1,3 , and 7 days in young vs. 3 days only in aged; IL-13 at $6 \mathrm{~h}$ in young vs. 1 and 3 days in aged rats. IL-4 was not significantly increased above control levels and instead was apparently suppressed early after ICH in aged rats $(6 \mathrm{~h})$. IL-13R $\alpha 2$ only increased above control levels in the young and only at 7 days.

Next, we monitored the expression of several wellknown markers of alternatively activated macrophages/ microglia: mannose receptor (MRC1/CD206), arginase 1 (ARG1), haptoglobin-hemoglobin scavenger receptor (CD163), and chemokine (C-C motif) ligand 22 (CCL22). In young adult rats, all four markers rapidly increased: by $6 \mathrm{~h}$ for CCL22 and by 1 day for the others. MRC1 and CD163 increased further with time, and while MRC1 was sustained until 7 days, the other genes decreased. There were several notable differences in the aged rats: MRC1 was induced later, but was higher at 7 days; ARG1 was lower at 1 day; CD163 was lower at 1 and 3 days, but higher at 7 days; and CCL22 was lower at $6 \mathrm{~h}$ and 1 day. Together, these results suggest that alternative activation was delayed in the aged animals. Because ARG1 metabolizes L-arginine to produce L-ornithine, which can be further metabolized into L-proline, a substrate for collagen synthesis [54], we examined the basal lamina component, collagen type IV (CgIV; Fig. 8). At 1 and 3 days after ICH, CgIV localized to blood microvessels, including fragmented vessels inside the hematoma. At 1 day, some white matter bundles inside the hematoma still stain for myelin basic protein, but they are swollen and disrupted, as we have previously shown [20]. Surprisingly, at 7 days, in addition to pronounced microvessel staining around the lesion, the core was filled with a more diffuse deposit of CgIV that appeared as a fibrotic clot. This response in the core was evident at 7 days in both young and aged animals, and there was no apparent difference in the time course of cgIV accumulation. Not all genes associated with alternative activation differed with age, e.g., chitinase 3-like 1 (CHI3L1), which can also induce alternative macrophage activation [55], was up-regulated at 1 and 3 days in both age groups.

\section{Discussion}

Despite the evidence that inflammation plays a crucial role in ICH pathology, surprisingly little is known about the timing of molecular changes, especially in aged rats. A microarray study on humans [56] and two on young adult rats $[57,58]$ examined a single time point $(24 \mathrm{~h})$ and noted changes in many immune-related molecules, including IL$1 \beta$, IL-1 receptor type 2 , IL-6 receptor, TGF $\beta$, TLR1, TNF receptor, IL-13R $\alpha 1$, IL-10 receptor $\beta$, interferon receptor 2 , macrophage inflammatory protein-2 precursor, prepro- complement $\mathrm{C} 3$, and $\mathrm{MHC}$ class II RT1-B region Ia antigen. Temporal changes in young rodents are beginning to be examined, but have been limited to a few proinflammatory (C3, CR2, IL-1 $\beta$, IL-6, interferon- $\gamma, \mathrm{NF}-\mathrm{KB}$, $\mathrm{TNF} \alpha$ ) and inflammation-resolving molecules (IL-10, TGF $\beta)[59,60]$. We previously analyzed several inflammatory genes (CR3, ICE, TACE, IL-1ra) and MMPs (MMP3, MMP9, MMP12) following ICH in young rats [21, 23], and the recent study on mice [59] is in good agreement with our results. The present study is unique in that it analyzes: (1) 27 genes selected to encompass a broad spectrum of inflammation-related molecules, including pro- and antiinflammatory mediators, tissue remodeling enzymes, and markers of different states of macrophage/microglia activation; (2) four time points ( $6 \mathrm{~h}$ and 1,3 , and 7 days) that bracket the secondary injury phase; (3) the ipsilateral and contralateral striatum, after normalizing to time-matched saline-injected control rats; and (4) young adult and aged rats at each time point.

Several cell types have the potential to produce inflammatory mediators after brain injury, including endogenous microglia and astrocytes, and infiltrating neutrophils and macrophages [61, 62]. Before discussing changes in gene expression, it is worth considering cellular responses, which have been mainly studied in young animals (reviewed in $[63,64])$. Neutrophils begin to infiltrate as early as $4 \mathrm{~h}[65]$ and are an important source of TNF $\alpha$ and IL-1 $\beta$ [66], which help recruit blood monocytes/macrophages [67]. Early microglial activation can occur in the peri-hematomal region $[63,68,69]$. In the ICH model used in this study (see ESM 
Fig. 8 Distribution of collagen type IV $(\mathrm{CgIV})$ staining after ICH. Representative confocal images of young (a) and aged (b) rats show myelin basic protein $(M B P$, green) labeling of white matter tracts and CgIV staining (red). The hematoma $(H)$ is readily seen as loss of MBP staining. At 1 and 3 days, CgIV localized to blood microvessels. At 7 days, the staining intensity greatly increased inside the lesion. Scale bars, $100 \mu \mathrm{m}$
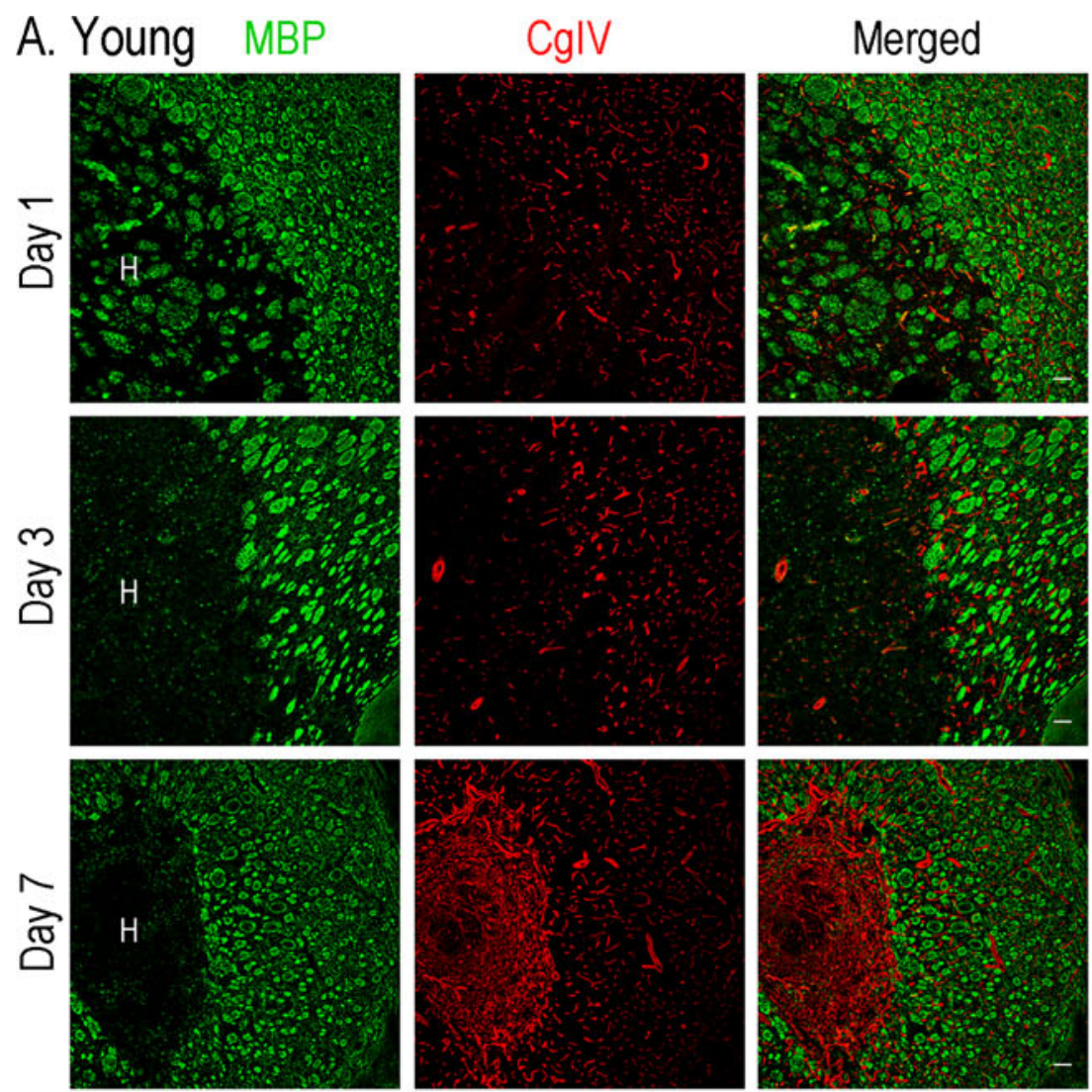

B. Aged

MBP

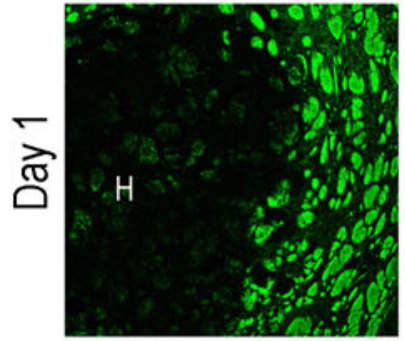

CgIV
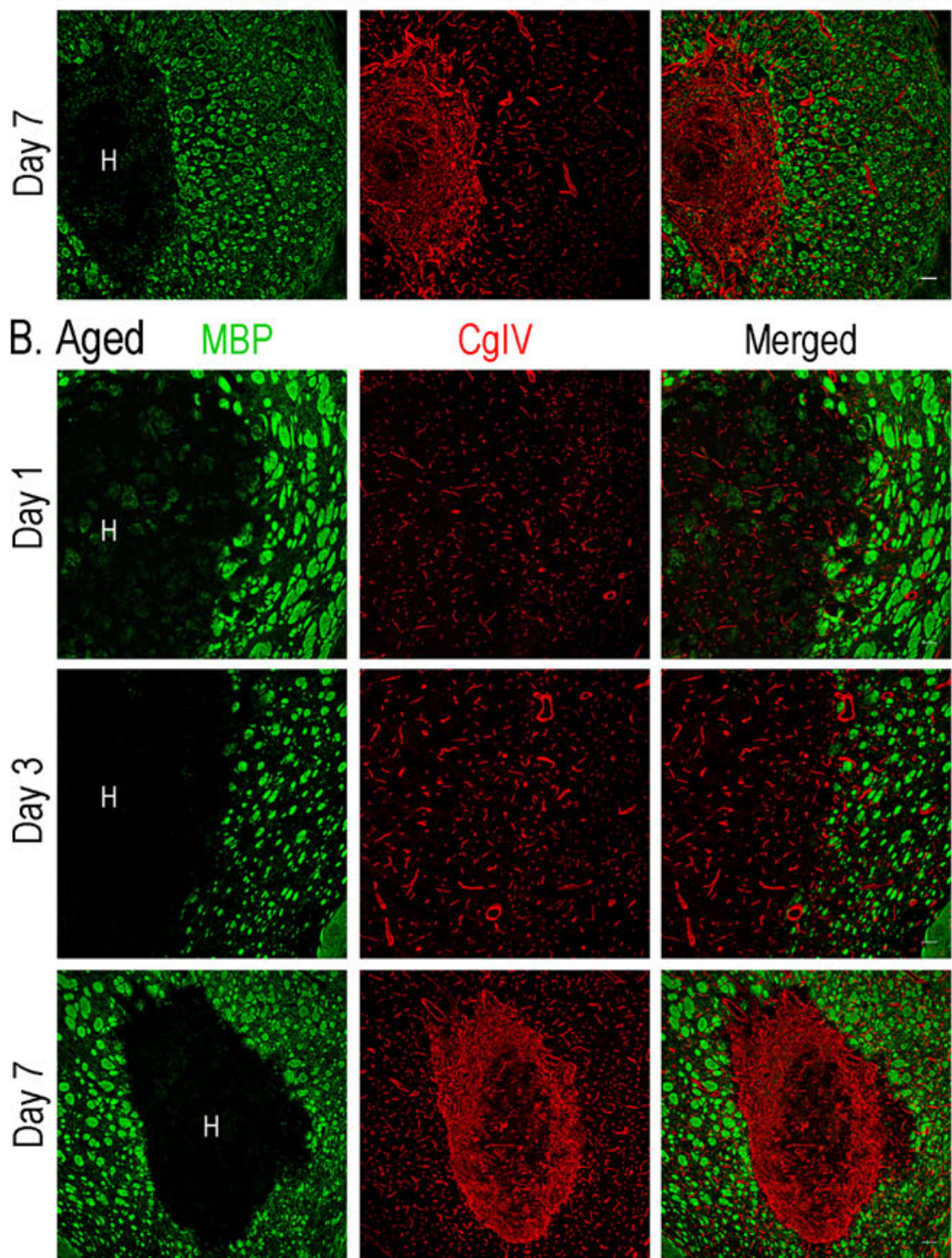

Merged
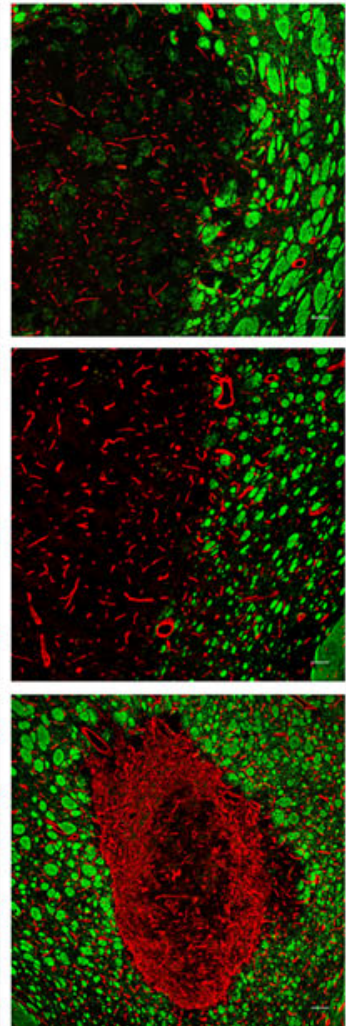
Fig. S1), we have observed a pronounced inflammatory response with rapid infiltration of neutrophils (within hours) and later activation of microglia and astrocytes, infiltration of blood monocytes/macrophages, and white matter damage. By 3 days after ICH induction, activated microglia, macrophages, and astrocytes formed a glial scar surrounding the hematoma. Neutrophil depletion reduced the activation of microglia, macrophages, and astrocytes and decreased BBB breakdown and axon damage [20]. Here, as early as $6 \mathrm{~h}$ after ICH in young adult rats, we observed increases in the expression of TLR2, IL-1 $\beta$, IL-1 ra, IL-1r2, iNOS, TNF $\alpha$, IL-6, MMP3, IL-13, IL-4R $\alpha$, and CCL22. These increases are too early for macrophage infiltration [70] and might be due to neutrophil infiltration (e.g., TNF $\alpha$ was mainly in neutrophils early after ICH $[20,21]$ ) or the responses of endogenous brain cells, including microglia, to blood products. Of note is that thrombin is produced in the brain immediately after $\mathrm{ICH}$, and it can induce microglia to secrete pro-inflammatory molecules (IL-1 $\beta, \mathrm{TNF} \alpha$ ) [71] and chemotactic factors that recruit blood leukocytes [72].

There are reports of poorer functional recovery after ICH in aged animals $[10,13,73]$ and histological differences, including reduced lesion resolution [11], more white matter damage [12], more severe edema and autophagy [10, 13], and decreased synaptogenesis and angiogenesis [74]. All of these factors likely contribute to poorer functional outcomes, but how might the inflammatory response contribute? Reduced neutrophil infiltration has been reported in aged rats after ICH [75], and we observed a more widespread distribution of ED1-labeled phagocytic microglia/ macrophages [11] (present study), especially in damaged white matter bundles [20]. Here, we found differences between young adult and aged rats in induced levels and/or timing for 18 of the 27 genes examined: TLR2, GFAP, IL$1 \beta$, IL-1ra, IL-1r2, iNOS, IL-6, TGF $\beta$, MMP9, MMP12, IL-13, IL-4R $\alpha$, IL-13R $\alpha 1$, IL-13R $\alpha 2$, MRC1, ARG1, CD163, CCL22. Most were delayed induction or lower levels in aged rats, with several differing as early as $6 \mathrm{~h}$ (TLR2, IL-1 $\beta$, IL-1ra, IL-1r2, iNOS, CCL22), and thus likely reflecting changes in neutrophil infiltration and dampened responses of endogenous brain cells. Given the many changes observed, rather than discussing every gene, we will focus on functional groupings, as in "Results."

As markers of the glial response, the induction of GFAP and TLR2 was delayed in aged rats, CR3/CD11b upregulation was reduced, and, at 7 days, ED1-labeled activated microglia/macrophages were more diffusely distributed in the surrounding striatum. IL-1 $\beta$ is a principal orchestrator of brain inflammation [37] which contributes to activating microglia [48], astrocytes [76-78], and endothelial cells [62] that then secrete IL-1 $\beta$ and other inflammatory molecules. IL-1 $\beta$ has been the focus of many experimental studies of ischemic stroke [79]. Intracerebroventricular or stereotaxic striatal injection of exogenous IL-1 $\beta$ exacerbated stroke-induced damage in young animals [80], and conversely, injury was reduced after the IL- $1 \beta$ antagonist, IL-1ra, was injected either locally into the striatum [81] or into an intracerebral ventricle [82]. Here, we found that early after ICH, young rats had a higher expression of IL-1 $\beta$ and its regulatory molecules, IL1 ra and IL-1r2, possibly as a compensatory response, as well as higher iNOS and IL-6 levels. In aged rats, the increase in IL-6 was delayed and TGF $\beta$ elevation was prolonged. Our results demonstrate the complexity and differences between young adult and aged rats in mediators generally associated with classical (or M1) macrophage/microglia activation.

In order to restore tissue homeostasis, it is expected that macrophage/microglia activation will shift from a proinflammatory gene profile to one that supports repair and tissue reconstruction. In peripheral tissue, this switch is induced primarily by the anti-inflammatory cytokines, IL4, IL-13, IL-10, and TGF $\beta$ (reviewed in [52, 53, 83, 84]). Interestingly, IL-4 knockout mice had a larger infarct volume and poorer neurological outcome after ischemic stroke [85]. In this first study of alternative activation markers after ICH or in aged animals, we observed the induction of IL-13 (by 1 day) and TGF $\beta$ (by 3 days) and a delay in aged rats. We previously showed IL-10 induction at $6 \mathrm{~h}$ and 7 days in young rats [23]. IL-4 was expressed in the striatum of control rats, but not increased after ICH. IL-4 and IL-13 bind to IL-4R $\alpha$ and IL-13R $\alpha 1$ chains in the type II receptor [83], and while it has been reported that IL-4 and IL-13 mRNA and protein levels in the brain are highly variable [86], IL-4 receptors are found on microglia and astrocytes [87]. IL-4R $\alpha$ and IL-13R $\alpha 1$ were up-regulated after ICH, but after a delay in the aged animals.

Consistent with the expression of stimuli and receptors that evoke alternative macrophage/microglia activation in vitro, ICH increased the expression of several markers: ARG1, MRC1/CD206, CD163, CCL22, CHI3L1, MMP12. ARG1 is notable because it competes with iNOS for L-arginine, but while iNOS generates potentially harmful levels of nitric oxide, ARG1 produces L-ornithine, indirectly reducing nitric oxide. Further ornithine metabolism produces L-proline, which is a substrate for collagen synthesis [54], and has been extensively studied in wound healing and pulmonary fibrosis. The massive, diffuse accumulation of collagen in the ICH lesion by day 7 suggests the presence of ARG1 activity and alternative activation. In aged animals, increases in ARG1, MRC1, and CD163 were delayed to between 3 and 7 days. Early induction of iNOS was also greatly reduced, and it is possible that ARG1 elevation was not needed to shift L-arginine metabolism away from nitric oxide production. Although delayed, the increase in MRC1 reached a much higher level on day 7 . MRC1 roles in the brain are not known, but it is important for pinocytosis and endocytosis by peripheral macrophages [84, 88]; its 
expression is low during the acute, pro-inflammatory phase and later up-regulated to help remove serum high-mannose glycoproteins [89]. Future studies will be needed to address whether increased MRC1 in aged rats corresponds with, and regulates, white matter-infiltrating macrophages and microglia.

MMP12 is induced in IL-4 stimulated macrophages [90, 91] and is a recently proposed marker of alternative activation [92]. MMP12 was the most highly up-regulated of the genes we analyzed after ICH. In young rats, there were marked increases in MMP12 expression [21, 27, 93] (present study), and at early times ( 1 and 3 days), it was present in astrocytes and around fragmented brain microvessels [21]. Here, we show that in aged rats, the increase was delayed (7 days), which correlates with the delayed expression of the alternative activation-related genes, MRC1, CD163, IL-4R $\alpha$, and IL-13R $\alpha$. While MMP12 functions in the brain are not known, there is some evidence for a deleterious role after ICH. MMP12-deficient mice had less microglia/macrophage recruitment to the hematoma and better sensorimotor recovery [93], and minocycline decreased MMP12 expression [21, 27], reduced edema and BBB leakiness [21], and improved the functional outcome [27]. Future studies will be needed to address whether agerelated changes in MMP12 reflect changes in alternatively activated macrophages/microglia.

Microglia/macrophage activation is thought to contribute to the worse injury and poorer outcomes in aged animals after ICH $[10,73]$. There are numerous reports that treatments inhibiting microglia/macrophage activation decrease hematoma volume and edema formation while improving neurological outcome [71, 94, 95]. However, the present study further illustrates the complexity of the innate inflammatory response in the first week after experimental ICH in which the induction of pro-inflammatory, potentially harmful mediators coincides temporally with many resolving and beneficial molecules. While this first study is necessarily descriptive, many time- and age-dependent changes were seen in the expression of inflammation-related genes, with many being reduced or delayed in aged rats. This evidence of a shift in the balance of inflammatory processes paves the way for further studies, including determining when, where, and in which cell types they are produced and how this expression changes with aging.

Acknowledgments We thank Xiaoping Zhu for conducting the realtime qPCR and Iska Moxon-Emre for performing animal surgeries. This work was supported by grants to LCS from the Heart \& Stroke Foundation, Ontario Chapter (no. T6279 and no. T6766), a Fellowship to SL from the Canadian Institutes for Health Research (no. MFE98546), and a scholarship to IM-E from the Canadian Institutes for Health Research.

Conflict of Interest The authors declare that they have no conflict of interest.
Open Access This article is distributed under the terms of the Creative Commons Attribution License which permits any use, distribution, and reproduction in any medium, provided the original author(s) and the source are credited.

\section{References}

1. Flower O, Smith M. The acute management of intracerebral hemorrhage. Curr Opin Crit Care. 2010;17:106-14.

2. Mayer SA, Rincon F. Treatment of intracerebral haemorrhage. Lancet Neurol. 2005;4:662-72.

3. Ariesen MJ, Claus SP, Rinkel GJ, Algra A. Risk factors for intracerebral hemorrhage in the general population: a systematic review. Stroke. 2003;34:2060-5.

4. Bejot Y, Osseby GV, Gremeaux V, Durier J, Rouaud O, Moreau T, Giroud M. Changes in risk factors and preventive treatments by stroke subtypes over 20 years: a population-based study. J Neurol Sci. 2009;287:84-8.

5. Collins TC, Petersen NJ, Menke TJ, Souchek J, Foster W, Ashton $\mathrm{CM}$. Short-term, intermediate-term, and long-term mortality in patients hospitalized for stroke. J Clin Epidemiol. 2003;56:81-7.

6. Thanvi B, Robinson T. Sporadic cerebral amyloid angiopathy-an important cause of cerebral haemorrhage in older people. Age Ageing. 2006;35:565-71.

7. van Asch CJ, Luitse MJ, Rinkel GJ, van der Tweel I, Algra A, Klijn CJ. Incidence, case fatality, and functional outcome of intracerebral haemorrhage over time, according to age, sex, and ethnic origin: a systematic review and meta-analysis. Lancet Neurol. 2010;9:16776.

8. Nguyen QC, Tabor JW, Entzel PP, Lau Y, Suchindran C, Hussey JM, Halpern CT, Harris KM, Whitsel EA. Discordance in national estimates of hypertension among young adults. Epidemiology. 2011;22:532-41.

9. Ruiz-Sandoval JL, Romero-Vargas S, Chiquete E, Padilla-Martinez JJ, Villarreal-Careaga J, Cantu C, Arauz A, Barinagarrementeria F. Hypertensive intracerebral hemorrhage in young people: previously unnoticed age-related clinical differences. Stroke. 2006;37:294650.

10. Gong Y, Hua Y, Keep RF, Hoff JT, Xi G. Intracerebral hemorrhage: effects of aging on brain edema and neurological deficits. Stroke. 2004;35:2571-5.

11. Wasserman JK, Yang H, Schlichter LC. Glial responses, neuron death and lesion resolution after intracerebral hemorrhage in young vs. aged rats. Eur J Neurosci. 2008;28:1316-28.

12. Wasserman JK, Schlichter LC. White matter injury in young and aged rats after intracerebral hemorrhage. Exp Neurol. 2008;214:266-75.

13. Gong Y, He Y, Gu Y, Keep RF, Xi G, Hua Y. Effects of aging on autophagy after experimental intracerebral hemorrhage. Acta Neurochir Suppl. 2011;111:113-7.

14. Xi G, Keep RF, Hoff JT. Mechanisms of brain injury after intracerebral haemorrhage. Lancet Neurol. 2006;5:53-63.

15. Lee EJ, Hung YC, Lee MY. Early alterations in cerebral hemodynamics, brain metabolism, and blood-brain barrier permeability in experimental intracerebral hemorrhage. J Neurosurg. 1999;91:10139.

16. Mayer SA, Lignelli A, Fink ME, Kessler DB, Thomas CE, Swarup R, Van Heertum RL. Perilesional blood flow and edema formation in acute intracerebral hemorrhage: a SPECT study. Stroke. 1998;29:1791-8.

17. Brott T, Broderick J, Kothari R, Barsan W, Tomsick T, Sauerbeck L, Spilker J, Duldner J, Khoury J. Early hemorrhage growth in patients with intracerebral hemorrhage. Stroke. 1997;28:1-5. 
18. Fujii Y, Tanaka R, Takeuchi S, Koike T, Minakawa T, Sasaki O. Hematoma enlargement in spontaneous intracerebral hemorrhage. J Neurosurg. 1994;80:51-7.

19. Kazui S, Naritomi H, Yamamoto H, Sawada T, Yamaguchi T. Enlargement of spontaneous intracerebral hemorrhage. Incidence and time course. Stroke. 1996;27:1783-7.

20. Moxon-Emre I, Schlichter LC. Neutrophil depletion reduces blood-brain barrier breakdown, axon injury, and inflammation after intracerebral hemorrhage. J Neuropathol Exp Neurol. 2011;70:218-35.

21. Wasserman JK, Schlichter LC. Minocycline protects the bloodbrain barrier and reduces edema following intracerebral hemorrhage in the rat. Exp Neurol. 2007;207:227-37.

22. Wasserman JK, Schlichter LC. Neuron death and inflammation in a rat model of intracerebral hemorrhage: effects of delayed minocycline treatment. Brain Res. 2007;1136:208-18.

23. Wasserman JK, Zhu X, Schlichter LC. Evolution of the inflammatory response in the brain following intracerebral hemorrhage and effects of delayed minocycline treatment. Brain Res. 2007;1180:140-54.

24. Masoro EJ. Mortality and growth characteristics of rat strains commonly used in aging research. Exp Aging Res. 1980;6:219-33.

25. Del Bigio MR, Yan HJ, Buist R, Peeling J. Experimental intracerebral hemorrhage in rats. Magnetic resonance imaging and histopathological correlates. Stroke. 1996;27:2312-9. discussion 9-20.

26. MacLellan CL, Auriat AM, McGie SC, Yan RH, Huynh HD, De Butte MF, Colbourne F. Gauging recovery after hemorrhagic stroke in rats: implications for cytoprotection studies. J Cereb Blood Flow Metab. 2006;26:1031-42.

27. Power C, Henry S, Del Bigio MR, Larsen PH, Corbett D, Imai Y, Yong VW, Peeling J. Intracerebral hemorrhage induces macrophage activation and matrix metalloproteinases. Ann Neurol. 2003;53:731-42.

28. Rosenberg GA, Mun-Bryce S, Wesley M, Kornfeld M. Collagenaseinduced intracerebral hemorrhage in rats. Stroke. 1990;21:801-7.

29. Hamann GF, Liebetrau M, Martens H, Burggraf D, Kloss CU, Bultemeier G, Wunderlich N, Jager G, Pfefferkorn T. Microvascular basal lamina injury after experimental focal cerebral ischemia and reperfusion in the rat. J Cereb Blood Flow Metab 2002;22: 526-33

30. Campuzano O, Castillo-Ruiz MM, Acarin L, Castellano B, Gonzalez B. Increased levels of proinflammatory cytokines in the aged rat brain attenuate injury-induced cytokine response after excitotoxic damage. J Neurosci Res. 2009;87:2484-97.

31. Sharman KG, Sharman EH, Yang E, Bondy SC. Dietary melatonin selectively reverses age-related changes in cortical cytokine mRNA levels, and their responses to an inflammatory stimulus. Neurobiol Aging. 2002;23:633-8

32. Sieber MW, Claus RA, Witte OW, Frahm C. Attenuated inflammatory response in aged mice brains following stroke. PLoS One. 2011;6:e26288.

33. Kaur C, Ling EA. Activation and re-expression of surface antigen in microglia following an epidural application of kainic acid in the rat brain. J Anat. 1992;180(Pt 2):333-42.

34. Morgan D, Gordon MN, Tan J, Wilcock D, Rojiani AM. Dynamic complexity of the microglial activation response in transgenic models of amyloid deposition: implications for Alzheimer therapeutics. J Neuropathol Exp Neurol. 2005;64:743-53.

35. Sofroniew MV, Vinters HV. Astrocytes: biology and pathology. Acta Neuropathol. 2010;119:7-35.

36. Li W, Gao G, Guo Q, Jia D, Wang J, Wang X, He S, Liang Q. Function and phenotype of microglia are determined by Toll-like receptor 2/Toll-like receptor 4 activation sequence. DNA Cell Biol. 2009;28:493-9.

37. Basu A, Krady JK, Levison SW. Interleukin-1: a master regulator of neuroinflammation. J Neurosci Res. 2004;78:151-6.
38. Black RA, Kronheim SR, Sleath PR. Activation of interleukin-1 $\beta$ by a co-induced protease. FEBS Lett. 1989;247:386-90.

39. Kostura MJ, Tocci MJ, Limjuco G, Chin J, Cameron P, Hillman AG, Chartrain NA, Schmidt JA. Identification of a monocyte specific pre-interleukin $1 \beta$ convertase activity. Proc Natl Acad Sci USA. 1989;86:5227-31.

40. Hannum CH, Wilcox CJ, Arend WP, Joslin FG, Dripps DJ, Heimdal PL, Armes LG, Sommer A, Eisenberg SP, Thompson RC. Interleukin-1 receptor antagonist activity of a human interleukin-1 inhibitor. Nature. 1990;343:336-40.

41. McMahan CJ, Slack JL, Mosley B, Cosman D, Lupton SD, Brunton LL, Grubin CE, Wignall JM, Jenkins NA, Brannan CI, et al. A novel IL-1 receptor, cloned from $\mathrm{B}$ cells by mammalian expression, is expressed in many cell types. EMBO J. 1991;10:2821-32.

42. Golde S, Chandran S, Brown GC, Compston A. Different pathways for iNOS-mediated toxicity in vitro dependent on neuronal maturation and NMDA receptor expression. J Neurochem. 2002;82:26982.

43. Satake K, Matsuyama Y, Kamiya M, Kawakami H, Iwata H, Adachi K, Kiuchi K. Nitric oxide via macrophage iNOS induces apoptosis following traumatic spinal cord injury. Brain Res Mol Brain Res. 2000;85:114-22.

44. Schlichter LC, Kaushal V, Moxon-Emre I, Sivagnanam V, Vincent C. The $\mathrm{Ca}^{2+}$ activated SK3 channel is expressed in microglia in the rat striatum and contributes to microglia-mediated neurotoxicity in vitro. J Neuroinflammation. 2010;7:4.

45. Yoo HS, Rutherford MS, Maheswaran SK, Srinand S, Ames TR. Induction of nitric oxide production by bovine alveolar macrophages in response to Pasteurella haemolytica A1. Microb Pathog. 1996;20:361-75.

46. Shohami E, Ginis I, Hallenbeck JM. Dual role of tumor necrosis factor alpha in brain injury. Cytokine Growth Factor Rev. 1999;10:119-30.

47. Moss ML, Jin SL, Becherer JD, Bickett DM, Burkhart W, Chen WJ, Hassler D, Leesnitzer MT, McGeehan G, Milla M, Moyer M, Rocque W, Seaton T, Schoenen F, Warner J, Willard D. Structural features and biochemical properties of TNF- $\alpha$ converting enzyme (TACE). J Neuroimmunol. 1997;72:127-9.

48. Basu A, Krady JK, O'Malley M, Styren SD, DeKosky ST, Levison SW. The type 1 interleukin-1 receptor is essential for the efficient activation of microglia and the induction of multiple proinflammatory mediators in response to brain injury. $\mathrm{J}$ Neurosci. 2002;22:6071-82.

49. Wahl SM. Transforming growth factor- $\beta$ : innately bipolar. Curr Opin Immunol. 2007;19:55-62.

50. Kohta M, Kohmura E, Yamashita T. Inhibition of TGF- $\beta 1$ promotes functional recovery after spinal cord injury. Neurosci Res. 2009;65:393-401.

51. Wang J. Preclinical and clinical research on inflammation after intracerebral hemorrhage. Prog Neurobiol. 2010;92:463-77.

52. Colton CA. Heterogeneity of microglial activation in the innate immune response in the brain. J Neuroimmune Pharmacol. 2009;4:399-418.

53. Gordon S. Alternative activation of macrophages. Nat Rev Immunol. 2003;3:23-35.

54. Hesse M, Modolell M, La Flamme AC, Schito M, Fuentes JM, Cheever AW, Pearce EJ, Wynn TA. Differential regulation of nitric oxide synthase- 2 and arginase- 1 by type 1/type 2 cytokines in vivo: granulomatous pathology is shaped by the pattern of Larginine metabolism. J Immunol. 2001;167:6533-44.

55. Lee CG, Hartl D, Lee GR, Koller B, Matsuura H, Da Silva CA, Sohn MH, Cohn L, Homer RJ, Kozhich AA, Humbles A, Kearley J, Coyle A, Chupp G, Reed J, Flavell RA, Elias JA. Role of breast regression protein 39 (BRP-39)/chitinase 3-like-1 in Th2 and IL-13-induced tissue responses and apoptosis. J Exp Med. 2009;206:1149-66. 
56. Carmichael ST, Vespa PM, Saver JL, Coppola G, Geschwind DH, Starkman S, Miller CM, Kidwell CS, Liebeskind DS, Martin NA. Genomic profiles of damage and protection in human intracerebral hemorrhage. J Cereb Blood Flow Metab. 2008;28:1860-75.

57. Lu A, Tang Y, Ran R, Ardizzone TL, Wagner KR, Sharp FR. Brain genomics of intracerebral hemorrhage. J Cereb Blood Flow Metab. 2006;26:230-52.

58. Tang Y, Lu A, Aronow BJ, Wagner KR, Sharp FR. Genomic responses of the brain to ischemic stroke, intracerebral haemorrhage, kainate seizures, hypoglycemia, and hypoxia. Eur J Neurosci. 2002;15:1937-52.

59. Liesz A, Middelhoff M, Zhou W, Karcher S, Illanes S, Veltkamp R. Comparison of humoral neuroinflammation and adhesion molecule expression in two models of experimental intracerebral hemorrhage. Exp Transl Stroke Med. 2011;3:11.

60. Zhang X, Li H, Hu S, Zhang L, Liu C, Zhu C, Liu R, Li C. Brain edema after intracerebral hemorrhage in rats: the role of inflammation. Neurol India. 2006;54:402-7.

61. Barone FC, Feuerstein GZ. Inflammatory mediators and stroke: new opportunities for novel therapeutics. J Cereb Blood Flow Metab. 1999;19:819-34.

62. Stanimirovic D, Satoh K. Inflammatory mediators of cerebral endothelium: a role in ischemic brain inflammation. Brain Pathol. 2000;10:113-26.

63. Wang J, Dore S. Inflammation after intracerebral hemorrhage. J Cereb Blood Flow Metab. 2007;27:894-908.

64. Weiss SJ. Tissue destruction by neutrophils. N Engl J Med. 1989;320:365-76.

65. Wang J, Tsirka SE. Contribution of extracellular proteolysis and microglia to intracerebral hemorrhage. Neurocrit Care. 2005;3:7785.

66. Cassatella MA, Gasperini S, Russo MP. Cytokine expression and release by neutrophils. Ann N Y Acad Sci. 1997;832:233-42.

67. Soehnlein O, Lindbom L. Phagocyte partnership during the onset and resolution of inflammation. Nat Rev Immunol. 2010;10:42739.

68. Hickenbottom SL, Grotta JC, Strong R, Denner LA, Aronowski J. Nuclear factor- $\mathrm{kB}$ and cell death after experimental intracerebral hemorrhage in rats. Stroke. 1999;30:2472-7. discussion 7-8.

69. Xue M, Del Bigio MR. Intracerebral injection of autologous whole blood in rats: time course of inflammation and cell death. Neurosci Lett. 2000;283:230-2.

70. Loftspring MC, McDole J, Lu A, Clark JF, Johnson AJ. Intracerebral hemorrhage leads to infiltration of several leukocyte populations with concomitant pathophysiological changes. J Cereb Blood Flow Metab. 2009;29:137-43

71. Wu J, Yang S, Xi G, Song S, Fu G, Keep RF, Hua Y. Microglial activation and brain injury after intracerebral hemorrhage. Acta Neurochir Suppl. 2008;105:59-65.

72. Aronowski J, Zhao X. Molecular pathophysiology of cerebral hemorrhage: secondary brain injury. Stroke. 2011;42:1781-6.

73. Lee JC, Cho GS, Choi BO, Kim HC, Kim YS, Kim WK. Intracerebral hemorrhage-induced brain injury is aggravated in senescence-accelerated prone mice. Stroke. 2006;37:216-22.

74. Zhang L, Zhang RL, Wang Y, Zhang C, Zhang ZG, Meng H, Chopp M. Functional recovery in aged and young rats after embolic stroke: treatment with a phosphodiesterase type 5 inhibitor. Stroke. 2005;36:847-52.

75. Gong Y, Xi G, Wan S, Gu Y, Keep RF, Hua Y. Effects of aging on complement activation and neutrophil infiltration after intracerebral hemorrhage. Acta Neurochir Suppl. 2008;105:67-70.

76. Herx LM, Yong VW. Interleukin- $1 \beta$ is required for the early evolution of reactive astrogliosis following CNS lesion. J Neuropathol Exp Neurol. 2001;60:961-71.
77. John GR, Chen L, Rivieccio MA, Melendez-Vasquez CV, Hartley A, Brosnan CF. Interleukin- $1 \beta$ induces a reactive astroglial phenotype via deactivation of the Rho GTPase-Rock axis. J Neurosci. 2004;24:2837-45.

78. Schultz J, Schwarz A, Neidhold S, Burwinkel M, Riemer C, Simon D, Kopf M, Otto M, Baier M. Role of interleukin-1 in prion disease-associated astrocyte activation. Am J Pathol. 2004; $165: 671-8$.

79. Fagan SC, Hess DC, Hohnadel EJ, Pollock DM, Ergul A. Targets for vascular protection after acute ischemic stroke. Stroke. 2004;35:2220-5.

80. Stroemer RP, Rothwell NJ. Exacerbation of ischemic brain damage by localized striatal injection of interleukin- $1 \beta$ in the rat. J Cereb Blood Flow Metab. 1998;18:833-9.

81. Stroemer RP, Rothwell NJ. Cortical protection by localized striatal injection of IL-1 ra following cerebral ischemia in the rat. J Cereb Blood Flow Metab. 1997;17:597-604.

82. Boutin H, LeFeuvre RA, Horai R, Asano M, Iwakura Y, Rothwell NJ. Role of IL- $1 \alpha$ and IL- $1 \beta$ in ischemic brain damage. J Neurosci. $2001 ; 21: 5528-34$.

83. Martinez FO, Helming L, Gordon S. Alternative activation of macrophages: an immunologic functional perspective. Annu Rev Immunol. 2009;27:451-83.

84. Varin A, Gordon S. Alternative activation of macrophages: immune function and cellular biology. Immunobiology. 2009;214: $630-41$.

85. Xiong X, Barreto GE, Xu L, Ouyang YB, Xie X, Giffard RG. Increased brain injury and worsened neurological outcome in interleukin-4 knockout mice after transient focal cerebral ischemia. Stroke. 2011;42:2026-32.

86. Ponomarev ED, Maresz K, Tan Y, Dittel BN. CNS-derived interleukin-4 is essential for the regulation of autoimmune inflammation and induces a state of alternative activation in microglial cells. J Neurosci. 2007;27:10714-21.

87. Kawakami M, Leland P, Kawakami K, Puri RK. Mutation and functional analysis of IL-13 receptors in human malignant glioma cells. Oncol Res. 2001;12:459-67.

88. Stahl PD, Ezekowitz RA. The mannose receptor is a pattern recognition receptor involved in host defense. Curr Opin Immunol. 1998; 10:50-5.

89. Lee SJ, Evers S, Roeder D, Parlow AF, Risteli J, Risteli L, Lee YC, Feizi T, Langen H, Nussenzweig MC. Mannose receptormediated regulation of serum glycoprotein homeostasis. Science. 2002;295:1898-901.

90. Gratchev A, Kzhyshkowska J, Utikal J, Goerdt S. Interleukin-4 and dexamethasone counterregulate extracellular matrix remodelling and phagocytosis in type-2 macrophages. Scand J Immunol. 2005;61:10 7.

91. Kahnert A, Seiler P, Stein M, Bandermann S, Hahnke K, Mollenkopf $\mathrm{H}$, Kaufmann SH. Alternative activation deprives macrophages of a coordinated defense program to mycobacterium tuberculosis. Eur J Immunol. 2006;36:631-47.

92. Gordon S, Martinez FO. Alternative activation of macrophages: mechanism and functions. Immunity. 2010;32:593-604.

93. Wells JE, Biernaskie J, Szymanska A, Larsen PH, Yong VW, Corbett D. Matrix metalloproteinase (MMP)-12 expression has a negative impact on sensorimotor function following intracerebral haemorrhage in mice. Eur J Neurosci. 2005;21:187-96.

94. Gao Z, Wang J, Thiex R, Rogove AD, Heppner FL, Tsirka SE. Microglial activation and intracerebral hemorrhage. Acta Neurochir Suppl. 2008;105:51-3.

95. Wang J, Rogove AD, Tsirka AE, Tsirka SE. Protective role of tuftsin fragment 1-3 in an animal model of intracerebral hemorrhage. Ann Neurol. 2003;54:655-64. 